\title{
Accelerating Sustainable Development Goals for South African adolescents from high HIV prevalence areas: a longitudinal path analysis
}

Franziska Meinck ${ }^{1,2,3^{*}}$ (D), Mark Orkin ${ }^{4}$ and Lucie Cluver ${ }^{5,6}$

\begin{abstract}
Background: Adolescents experience a multitude of vulnerabilities which need to be addressed in order to achieve the Sustainable Development Goals (SDGs). In sub-Saharan Africa, adolescents experience high burden of HIV, violence exposure, poverty, and poor mental and physical health. This study aimed to identify interventions and circumstances associated with three or more targets ("accelerators") within multiple SDGs relating to HIV-affected adolescents and examine cumulative effects on outcomes.

Methods: Prospective longitudinal data from 3401 adolescents from randomly selected census enumeration areas in two provinces with > 30\% HIV prevalence carried out in 2010/11 and 2011/12 were used to examine six hypothesized accelerators (positive parenting, parental monitoring, free schooling, teacher support, food sufficiency and HIV-negative/asymptomatic caregiver) targeting twelve outcomes across four SDGs, using a multivariate (multiple outcome) path model with correlated outcomes controlling for outcome at baseline and sociodemographics. The study corrected for multiple-hypothesis testing and tested measurement invariance across sex. Percentage predicted probabilities of occurrence of the outcome in the presence of the significant accelerators were also calculated.
\end{abstract}

Results: Sample mean age was 13.7 years at baseline, 56.6\% were female. Positive parenting, parental monitoring, food sufficiency and AIDS-free caregiver were variously associated with reductions on ten outcomes. The model was gender invariant. AIDS-free caregiver was associated with the largest reductions. Combinations of accelerators resulted in a percentage reduction of risk of up to $40 \%$.

Conclusion: Positive parenting, parental monitoring, food sufficiency and AIDS-free caregivers by themselves and in combination improve adolescent outcomes across ten SDG targets. These could translate to the corresponding real-world interventions parenting programmes, cash transfers and universal access to antiretroviral treatment, which when provided together, may help governments in sub-Saharan Africa more economically to reach their SDG targets.

\footnotetext{
* Correspondence: Franziska.Meinck@ed.ac.uk

'School of Social and Political Sciences, University of Edinburgh, 15a George Square, Edinburgh EH8 9LD, UK

${ }^{2}$ OPTENTIA, Faculty of Humanities, North-West University, Vanderbij|park, South Africa

Full list of author information is available at the end of the article
}

(c) The Author(s). 2021 Open Access This article is licensed under a Creative Commons Attribution 4.0 International License, which permits use, sharing, adaptation, distribution and reproduction in any medium or format, as long as you give appropriate credit to the original author(s) and the source, provide a link to the Creative Commons licence, and indicate if changes were made. The images or other third party material in this article are included in the article's Creative Commons licence, unless indicated otherwise in a credit line to the material. If material is not included in the article's Creative Commons licence and your intended use is not permitted by statutory regulation or exceeds the permitted use, you will need to obtain permission directly from the copyright holder. To view a copy of this licence, visit http://creativecommons.org/licenses/by/4.0/. The Creative Commons Public Domain Dedication waiver (http://creativecommons.org/publicdomain/zero/1.0/) applies to the data made available in this article, unless otherwise stated in a credit line to the data. 
Keywords: Accelerators, Sustainable Development Goals, Violence prevention, Adolescents, Parenting, Food sufficiency, HIV/AIDS, Child abuse, Social protection, Mental health

\section{Background}

Adolescents make up 23\% of Africa's population, and Africa's adolescents are the fastest growing population group in the world [1]. However, they experience a multitude of vulnerabilities which often go unaddressed. These include increased risk for loss of a parent or illness of a parent due to AIDS and the associated vulnerabilities [2], HIV infection among girls [3] as well as exposure to violence [4], early child bearing [5], poor mental health [6], and challenges in accessing and remaining in education [7]. Urgent intervention at the government and policy level is needed to attain the Sustainable Development Goals (SDGs) in this region and ensure adolescents reach their full potential.

Reaching all the SDG targets in the nine years that remain until 2030 is a major challenge for all governments. Development accelerators, promoted by UNDP, are considered to be a new approach which could help governments deliver across targets and goals [8]. UNDP define accelerators as "pragmatic actions"-in practice, interventions such as parenting programmes, or circumstances such as adequate food provision-that have a beneficial association with multiple SDG outcomes [9]. Accelerators are therefore provisions, protective factors or interventions which reduce poor outcomes for adolescents on at least three sustainable SDG targets. For example, a recent study from South Africa with HIVpositive adolescents showed that supportive parenting was associated with good mental health and no violence perpetration, no high-risk sex, no community violence exposure nor physical or emotional child abuse (SDGs $3.3,3.4,5.2,16.2,16.1$ and 16.2 respectively )[10]. Therefore, supportive parenting was considered an accelerator as it was associated with reductions across five SDG targets. In addition, this study showed substantial additive effects where different accelerators together were associated with significant improvements on a particular outcome. However, studies have been lacking that investigate accelerators of adolescents in contexts with high parental HIV prevalence, which has been shown to be associated with poor child health outcomes and other vulnerabilities [11].

The present study therefore has four aims: (1) to investigate the association of six pragmatic actions with twelve SDG target outcomes and to identify any accelerators among these pragmatic actions in a sample of South African adolescents in areas with high HIV prevalence; (2) to take account of correlations among the outcomes as necessary; (3) to check for moderation of associations by respondents' sex; and (4) to test additive effects of combined accelerators on SDG target outcomes.

\section{Methods \\ Procedure}

We consulted prior to baseline with local traditional leaders, local provincial government, pre-piloted with adolescents from these population groups, and introduced the study at multiple community meetings. The design of the study and questionnaire was carried out in consultation with our South African Teen Advisory Group [12].

\section{Participants}

Adolescents $(n=3516)$ aged $10-17$ (56.7\% female) were recruited from urban and rural areas in two South African provinces, interviewed at baseline (2010-2011) and followed up 1 year later. Refusal rate at baseline was < $2.5 \%$, and retention rate at one-year follow-up was $96.8 \%$. Door-to-door sampling was used to recruit adolescents in randomly selected census enumeration areas across four health districts with antenatal HIV prevalence $>30 \%$. Areas were highly deprived and previously disadvantaged homelands or townships. In 70-min faceto-face interviews, one randomly selected adolescent was interviewed per household, by interviewers trained in working with vulnerable youth. No exclusion criteria were applied unless the adolescent was deemed incapable of giving consent or understanding the questionnaire. Informed consent was sought from the primary caregiver and assent from the adolescent. Consent forms and questionnaires were translated into the six local languages and checked with back translation.

Ethical clearance was provided by the provincial government departments of Health and Education, the Universities of Oxford (SSD/CUREC2/09-52), Cape Town (389/209) and KwaZulu-Natal (HSS/0254/09). Participants were interviewed in private spaces such as gardens to ensure privacy and confidentiality. Confidentiality was maintained throughout the study except where participants requested help or were at risk of significant harm, where referrals, in line with mandatory reporting requirements, were made to health or statutory child protective services with follow-up support. We supported children to disclose to their caregivers where these were not the cause of harm. All participants received a certificate and refreshments. 


\section{Measures}

\section{SDG outcomes}

SDG outcomes were binary. SDG 16.2 Physical abuse in the past year was measured using two items from the UNICEF Scales for National-Level Monitoring of Orphans and Other Vulnerable Children [13]. SDG 16.2 Emotional abuse in the past year was measured using three items from the same measure. SDG 5.2 Sexual abuse was measured using two items from the Juvenile Victimization Questionnaire [14]. Items were dichotomized into pastyear abuse experience vs none. SDG 4.A Bullying $(\alpha=.81)$ was measured using the 8-item Social and Health Assessment Peer Victimization Scale [15]. A cut-off of 9 was used to define experience of bullying vs no bullying. SDG 5.2 Witnessing domestic violence was measured using one item as one or more incidents in which adults were hitting or shouting at each other violently in the home in the past week [13]. SDG 16.1 Exposure to Community Violence in the form of ever being robbed or assaulted was measured using two items from the Child Exposure to Community Violence (CECV) Checklist [16] and defined as one or more incidents. SDG 16.1 Experience of Community Violence through ever witnessing a shooting or stabbing was also measured using two binary items from the CECV and defined as occurrence vs no occurrence. SDG 3.3 TB symptomology was assessed using an 8-item TB symptom checklist with two or more symptoms of chest pains, coughing blood and cough for three weeks defined as TB symptomatic taken from the KwaZulu-Natal Department of Health TB symptom guidelines. SDG 3.4 Suicidal ideation and attempts during the past month were measured using the Mini International Psychiatric Interview for Children and Adolescents (MINI-KID) [17] which has been previously used in South Africa and showed acceptable internal consistency in this sample $(\alpha=.73)$ and defined as $1+$ endorsements of five items. SDG 5.61 HIV risk behaviour was measured using three binary items from the National Survey of HIV and Sexual Behaviour among Young South Africans [18] measuring sex before age 15, having sex drunk or on drugs, and transactional sex and one item from the South African Demographic and Health Survey [19] on sex with partners 5+ years older, and was defined as engaging in one or more of these behaviours. SDG 3.5 Alcohol and drug use in the past month was measured using two items from the National Survey of HIV and Risk Behaviours among Young South Africans [18] measuring alcohol use and use of seven common substances and defined as using one or more of these substances. SDG 4.1 School Dropout was measured as child no longer enrolled in school.

\section{Hypothesized accelerators}

All hypothesized accelerators were required to have been provided at both baseline and follow-up and were binary.
An accelerator was defined as an intervention or circumstance that has a beneficial association with three or more SDG targets as calculated through the study analysis [9]. Positive Parenting was measured using the 4item subscale from the Alabama Parenting Questionnaire Short Form (APQ-SF )[20], and defined as children reporting receipt of positive parenting always or mostly on all items. Parental Monitoring was measured using the 3-item subscale from the APQ-SF and defined as children reporting receipt of good monitoring always or mostly on all items. Food sufficiency was measured as child reporting neither going to bed hungry nor being hungry at school in the past 7 days. AIDS-free caregiver was measured using Verbal Autopsy methods validated in previous studies of adult mortality in South Africa [21]. The Verbal Autopsy is an 18-item checklist of current common health conditions and AIDS-defining illnesses. Determination of caregiver HIV/AIDS-symptomology required endorsement of three or more AIDSdefining illnesses (i.e. tuberculosis, shingles or Kaposi's sarcoma). Teacher emotional support was measured using the 2 items from the Social Support Scale and defined as having a teacher who provides very good emotional or instrumental support [22]. Free schooling was defined as attending a no-fees school, receiving a free school meal and free textbooks at the same time at both baseline and follow-up. Attendance at no-fees schools was almost universal but provision of free school meals and free textbooks varied by school independent of parental income. All measures have been previously used in South Africa.

\section{Pre-selected covariates}

Hypothesized accelerators at baseline were measured with the above items. Urban/rural location, province, informal housing, sex and age were measured with categories from the South African census [23].

\section{Analysis}

Analyses were conducted in seven stages using Stata 15 and Mplus 8.3 (all syntax can be found in Additional File 2). First, descriptive statistics were calculated for all hypothesized accelerators, SDG outcomes and covariates (Table 1) in Stata 15.1. Second, associations between all variables were checked in a correlation matrix (Additional File 1: Supplement 1) to assess if correlation of outcomes would be required [24]. Third, multivariate (multiple-outcome) probit regressions were conducted in MPlus 8.0 to identify potential accelerators, by entering all chosen SDG outcomes and hypothesized accelerator variable and covariates (baseline exposure, age, province, urban location, informal housing and sex) simultaneously as a path model (Table 2). The model included the Mplus command for correlation among all 
Table 1 Sociodemographic characteristics of the study sample $(N=3401)$

\begin{tabular}{|c|c|c|c|c|}
\hline & Total $n=3401$ & Boys $n=1475$ (43.4\%) & Girls $n=1926$ (56.6\%) & Sex difference $p$ value \\
\hline \multicolumn{5}{|l|}{ Sociodemographic characteristics at baseline } \\
\hline Province & & & & 0.030 \\
\hline Western Cape & $1753(51.5 \%)$ & $729(41.6 \%)$ & $1024(58.4 \%)$ & \\
\hline Mpumalanga & $1648(48.5 \%)$ & $746(45.3 \%)$ & $902(54.7 \%)$ & \\
\hline Age & & & & 0.615 \\
\hline Mean (SD) & $13.43(2.14)$ & $13.4(2.10)$ & $13.44(2.18)$ & \\
\hline Rural location & & & & 0.238 \\
\hline Yes & $1681(49.4 \%)$ & $712(42.4 \%)$ & $969(57.6 \%)$ & \\
\hline Informal housing & & & & 0.153 \\
\hline Yes & $1068(31.4 \%)$ & $444(41.6 \%)$ & $624(58.4)$ & \\
\hline \multicolumn{5}{|c|}{ Hypothesized protective factors received at both $\mathrm{T} 1$ and $\mathrm{T} 2$} \\
\hline Positive parenting & & & & 0.502 \\
\hline Yes & $875(25.7 \%)$ & $371(42.4 \%)$ & $504(57.6 \%)$ & \\
\hline Parental monitoring & & & & $<0.001$ \\
\hline Yes & $2677(78.7 \%)$ & $1105(41.2 \%)$ & $1572(58.7 \%)$ & \\
\hline Food sufficiency at home & & & & 0.776 \\
\hline Yes & $2829(83.2 \%)$ & $1230(43.48)$ & $1599(56.5 \%)$ & \\
\hline HIV-/ asymptomatic caregiver & & & & 0.057 \\
\hline Yes & 3198 (94.0\%) & $1400(43.8 \%)$ & $1798(56.2 \%)$ & \\
\hline Teacher support & & & & 0.365 \\
\hline Yes & $569(16.7 \%)$ & $237(41.7 \%)$ & $332(58.4 \%)$ & \\
\hline Free school meals, textbooks and no fees & & & & 0.243 \\
\hline Yes & $1329(39.1 \%)$ & $560(42.1 \%)$ & $769(57.8 \%)$ & \\
\hline \multicolumn{5}{|l|}{ SDG outcomes at T2 } \\
\hline Physical abuse & & & & 0.226 \\
\hline Yes & $1289(37.9 \%)$ & $576(44.7 \%)$ & $713(55.31)$ & \\
\hline Emotional abuse & & & & 0.004 \\
\hline Yes & $1076(31.6 \%)$ & $428(39.8 \%)$ & $648(60.2 \%)$ & \\
\hline Sexual abuse & & & & 0.001 \\
\hline Yes & $295(8.7 \%)$ & $101(34.2 \%)$ & $194(65.8 \%)$ & \\
\hline Bullying & & & & 0.022 \\
\hline Yes & $2494(73.3 \%)$ & $1111(44.6 \%)$ & $1383(55.5 \%)$ & \\
\hline Domestic violence witnessing & & & & 0.002 \\
\hline Yes & $535(15.7 \%)$ & $200(37.4 \%)$ & $335(62.6 \%)$ & \\
\hline Community violence exposure & & & & 0.723 \\
\hline Yes & $1312(38.6 \%)$ & $574(43.8 \%)$ & $738(56.3 \%)$ & \\
\hline Community violence witnessing & & & & 0.124 \\
\hline Yes & $1338(39.3 \%)$ & $602(45.0 \%)$ & $736(55.0 \%)$ & \\
\hline Suicidal ideation & & & & $<0.001$ \\
\hline Yes & $614(18.1 \%)$ & $213(34.7 \%)$ & $401(65.7 \%)$ & \\
\hline HIV risk behaviour & & & & $<0.001$ \\
\hline Yes & $443(13.0 \%)$ & $251(56.7 \%)$ & $192(43.3 \%)$ & \\
\hline TB symptomatic & & & & 0.105 \\
\hline Yes & $176(5.2 \%)$ & $66(37.5 \%)$ & $110(62.5 \%)$ & \\
\hline
\end{tabular}


Table 1 Sociodemographic characteristics of the study sample $(N=3401)$ (Continued)

\begin{tabular}{|c|c|c|c|c|}
\hline & Total $n=3401$ & Boys $n=1475$ (43.4\%) & Girls $n=1926(56.6 \%)$ & Sex difference $p$ value \\
\hline Substance use & & & & $<0.001$ \\
\hline Yes & $249(7.3 \%)$ & $143(57.4 \%)$ & $106(42.6 \%)$ & \\
\hline School dropout & & & & 0.046 \\
\hline Yes & $147(4.3 \%)$ & $52(35.4 \%)$ & $95(64.6 \%)$ & \\
\hline
\end{tabular}

outcomes (Fig. 1). Standardized correlation coefficients for SDG outcomes are reported in Supplement 2 (Additional File 1). Fourth, to check for possible moderation of paths by participant sex, path invariance was tested between the configural model and the model with all paths constrained to equality across the two groups, using the Mplus DIFFTEST command. Fifth, to account for multiple-hypothesis testing and risk of type I error, the Benjamini-Hochberg procedure was used with a specified false discovery rate of 0.05 [25]. Sixth, all predictors which were positively associated with at least three SDG outcomes were defined as accelerators. Finally, predicted probabilities were calculated for instances where two or more accelerators were associated with a given outcome, holding covariates at their mean value, and probabilities were extracted for different summative combinations of accelerators on SDG outcomes (Table 3). These analyses in MPlus were conducted using weighted least squares and variance adjusted (WLSMV) estimation, due to categorical data for the SDG outcomes. Model fit was assessed using $\chi^{2} / \mathrm{df}$, comparative fit index (CFI), TuckerLewis Index (TLI), root mean square error of approximation (RMSEA) and weighted root mean square residual (WRMR). By convention, the maximum acceptable value for $\chi^{2} / \mathrm{df}$ is 5 . A value of $>.95$ indicates good fit for CFI and TLI, < .05 for RMSEA and > 0.95 for WRMR [26]. Missing data were less than $1 \%$ on all variables and thus no imputation was conducted; but pairwise deletion was used as the standard with the WLSMV estimator.

\section{Results}

Sociodemographic characteristics and prevalence of accelerators and SDG outcomes are shown in Table 1.

\section{Correlation matrix}

Pairwise correlations between variables ranged from insignificant to $r=.338$ for physical and emotional abuse (Additional File 1: Supplement 1).

\section{Path analysis (Table 2 and Supplement 2)}

The path model simultaneously containing all chosen SDG outcomes, hypothesized accelerator variables and covariates with correlated outcomes showed good model fit $\left(\chi^{2}=258.387, \mathrm{df}=132, p<001\right.$, CFI .967, TLI .914, RMSEA .017, WRMR .878). Table 2 displays the respective associations with the twelve outcomes. For example, reductions in physical abuse were predicted by positive parenting, food sufficiency, AIDS-free caregiver and parental good monitoring but not by teacher support nor free schooling.

\section{Gender invariance}

Moderation of paths by sex was tested through path invariance analysis. The path invariance model, i.e. with the respective paths in the models for males and females set to equal each other, fit the data as well as the configural model: The Mplus DIFFTEST yielded $\Delta \chi^{2}(\mathrm{df})=$ 115.887(132), $p=0.840$, meaning that moderation of paths by sex was not significant.

\section{Accelerator analysis}

The Benjamini-Hochberg [25] procedure did not eliminate any predictors. Four development accelerators were identified, each positively associated with three or more SDG targets. Positive parenting was associated with less physical abuse, emotional abuse, substance use and suicidal ideation (SDGs 16.2, 3.4 and 3.5). High parental monitoring was associated with less physical abuse, emotional abuse, HIV risk behaviour, bullying, substance use and experiencing community violence (SDGs, 16.2, 5.61, 4.A, 3.5, 16.1). Having an AIDS-free caregiver was associated with less physical abuse, emotional abuse, experiencing community violence, suicidal ideation, bullying, witnessing domestic violence, TB symptomology and HIV risk behaviour (SDGs 16.2, 16.1, 3.4, 4.A, 5.2, 3.3, 5.61). Food sufficiency was associated with less physical abuse, emotional abuse, witnessing domestic violence, suicidal ideation, bullying, witnessing community violence, experiencing community violence and HIV risk behaviour (SDGs 16.2, 5.2, 3.4, 4.A, 16.1, 5.61). Free schooling and teacher support were not found to be accelerators (Table 2).

Correlations among outcomes in the path model, as compared with the pairwise correlations, proved to be quite substantial for physical and emotional abuse $(r=$ $0.52)$, school dropout and physical abuse $(r=0.52)$, HIV risk behaviour and sexual abuse $(r=0.44)$ and substance use and HIV risk behaviour $(r=0.41)$. Other correlations were either weak or not statistically significant (Additional File 1: Supplement 2). 
Table 2: Path model using multivariate probit regressions with correlated outcomes reporting standardized coefficients using the WLSMV estimator $(n=3396)$

\begin{tabular}{|c|c|c|c|c|}
\hline & Coefficient & $95 \% \mathrm{Cl}$ & S.E. & $p$ value \\
\hline \multicolumn{5}{|l|}{ Physical abuse } \\
\hline Positive parenting & -0.066 & -0.11 to -0.022 & 0.022 & 0.003 \\
\hline Food sufficiency & -0.056 & -0.098 to -0.013 & 0.022 & 0.010 \\
\hline AIDS-free caregiver & -0.107 & -0.147 to -0.067 & 0.020 & 0.000 \\
\hline Parental monitoring & -0.083 & -0.126 to -0.039 & 0.022 & 0.000 \\
\hline Teacher support & -0.013 & $-0.057-0.03$ & 0.022 & 0.546 \\
\hline Free schooling & 0.048 & $0.002-0.093$ & 0.023 & 0.043 \\
\hline Baseline physical abuse & 0.079 & $0.033-0.125$ & 0.023 & 0.001 \\
\hline Age & -0.154 & -0.2 to -0.108 & 0.023 & 0.000 \\
\hline Province & 0.230 & $0.168-0.292$ & 0.032 & 0.000 \\
\hline Urban location & 0.057 & $0.011-0.103$ & 0.023 & 0.015 \\
\hline Informal housing & -0.008 & $-0.061-0.044$ & 0.027 & 0.758 \\
\hline Sex & -0.011 & $-0.053-0.032$ & 0.022 & 0.625 \\
\hline \multicolumn{5}{|l|}{ Emotional abuse } \\
\hline Positive parenting & -0.074 & -0.12 to -0.027 & 0.024 & 0.002 \\
\hline Food sufficiency & -0.095 & -0.138 to -0.052 & 0.022 & 0.000 \\
\hline AIDS-free caregiver & -0.127 & -0.168 to -0.085 & 0.021 & 0.000 \\
\hline Parental monitoring & -0.085 & -0.129 to -0.04 & 0.023 & 0.000 \\
\hline Teacher support & 0.038 & $-0.006-0.082$ & 0.023 & 0.091 \\
\hline Free schooling & 0.020 & $-0.027-0.068$ & 0.024 & 0.405 \\
\hline Baseline emotional abuse & 0.092 & $0.044-0.141$ & 0.025 & 0.000 \\
\hline Age & 0.008 & $-0.041-0.056$ & 0.025 & 0.758 \\
\hline Province & -0.007 & $-0.072-0.059$ & 0.033 & 0.844 \\
\hline Urban location & 0.028 & $-0.019-0.076$ & 0.024 & 0.247 \\
\hline Informal housing & -0.050 & $-0.103-0.003$ & 0.027 & 0.066 \\
\hline Sex & 0.059 & $0.014-0.103$ & 0.023 & 0.010 \\
\hline \multicolumn{5}{|l|}{ Sexual abuse } \\
\hline Positive parenting & -0.064 & $-0.131-0.002$ & 0.034 & 0.058 \\
\hline Food sufficiency & -0.046 & $-0.108-0.015$ & 0.031 & 0.141 \\
\hline AIDS-free caregiver & -0.045 & $-0.101-0.012$ & 0.029 & 0.122 \\
\hline Parental monitoring & -0.040 & $-0.101-0.02$ & 0.031 & 0.190 \\
\hline Teacher support & 0.009 & $-0.054-0.072$ & 0.032 & 0.772 \\
\hline Free schooling & -0.002 & $-0.068-0.065$ & 0.034 & 0.961 \\
\hline Baseline sexual abuse & 0.135 & $0.091-0.179$ & 0.023 & 0.000 \\
\hline Age & 0.138 & $0.07-0.206$ & 0.035 & 0.000 \\
\hline Province & 0.211 & $0.122-0.299$ & 0.045 & 0.000 \\
\hline Urban location & 0.028 & $-0.039-0.096$ & 0.034 & 0.411 \\
\hline Informal housing & -0.097 & -0.177 to -0.017 & 0.041 & 0.018 \\
\hline Sex & 0.105 & $0.042-0.167$ & 0.032 & 0.001 \\
\hline \multicolumn{5}{|c|}{ Witnessing domestic violence } \\
\hline Positive parenting & -0.027 & $-0.081-0.028$ & 0.028 & 0.335 \\
\hline Food sufficiency & -0.112 & -0.16 to -0.064 & 0.025 & 0.000 \\
\hline AIDS-free caregiver & -0.067 & -0.114 to -0.021 & 0.024 & 0.004 \\
\hline
\end{tabular}


Table 2: Path model using multivariate probit regressions with correlated outcomes reporting standardized coefficients using the WLSMV estimator $(n=3396)$ (Continued)

\begin{tabular}{|c|c|c|c|c|}
\hline & Coefficient & $95 \% \mathrm{Cl}$ & S.E. & $p$ value \\
\hline Parental monitoring & 0.000 & $-0.054-0.055$ & 0.028 & 0.993 \\
\hline Teacher support & -0.032 & $-0.086-0.022$ & 0.028 & 0.244 \\
\hline Free schooling & -0.025 & $-0.083-0.032$ & 0.029 & 0.392 \\
\hline Baseline domestic violence & 0.112 & $0.059-0.165$ & 0.027 & 0.000 \\
\hline Age & -0.043 & $-0.098-0.011$ & 0.028 & 0.121 \\
\hline Province & -0.114 & -0.189 to -0.039 & 0.038 & 0.003 \\
\hline Urban location & -0.113 & -0.167 to -0.058 & 0.028 & 0.000 \\
\hline Informal housing & -0.022 & $-0.081-0.038$ & 0.030 & 0.472 \\
\hline Sex & 0.067 & $0.015-0.12$ & 0.027 & 0.012 \\
\hline \multicolumn{5}{|l|}{ Bullying } \\
\hline Positive parenting & 0.030 & $-0.017-0.078$ & 0.024 & 0.213 \\
\hline Food sufficiency & -0.077 & -0.124 to -0.031 & 0.024 & 0.001 \\
\hline AIDS-free caregiver & -0.072 & -0.121 to -0.023 & 0.025 & 0.004 \\
\hline Parental monitoring & -0.069 & -0.116 to -0.022 & 0.024 & 0.004 \\
\hline Teacher support & -0.043 & $-0.087-0.002$ & 0.023 & 0.062 \\
\hline Free schooling & 0.042 & $-0.007-0.092$ & 0.025 & 0.091 \\
\hline Baseline bullying & 0.128 & $0.083-0.173$ & 0.023 & 0.000 \\
\hline Age & -0.109 & -0.156 to -0.061 & 0.024 & 0.000 \\
\hline Province & -0.013 & $-0.081-0.055$ & 0.035 & 0.711 \\
\hline Urban location & -0.158 & -0.206 to -0.111 & 0.024 & 0.000 \\
\hline Informal housing & 0.034 & $-0.021-0.09$ & 0.028 & 0.224 \\
\hline Sex & -0.045 & $-0.091-0.001$ & 0.023 & 0.053 \\
\hline \multicolumn{5}{|l|}{ Witnessing community violence } \\
\hline Positive parenting & -0.030 & $-0.071-0.01$ & 0.021 & 0.145 \\
\hline Food sufficiency & -0.059 & -0.095 to -0.023 & 0.018 & 0.001 \\
\hline AIDS-free caregiver & -0.021 & $-0.061-0.019$ & 0.020 & 0.299 \\
\hline Parental monitoring & -0.035 & $-0.073-0.003$ & 0.020 & 0.073 \\
\hline Teacher support & 0.038 & $-0.002-0.077$ & 0.020 & 0.063 \\
\hline Free schooling & 0.001 & $-0.039-0.041$ & 0.021 & 0.954 \\
\hline Baseline wit. community violence & 0.148 & $0.11-0.186$ & 0.020 & 0.000 \\
\hline Age & 0.108 & $0.068-0.148$ & 0.021 & 0.000 \\
\hline Province & -0.539 & -0.584 to -0.493 & 0.023 & 0.000 \\
\hline Urban location & -0.054 & -0.094 to -0.013 & 0.021 & 0.009 \\
\hline Informal housing & -0.025 & $-0.068-0.018$ & 0.022 & 0.261 \\
\hline Sex & -0.051 & -0.09 to -0.013 & 0.020 & 0.009 \\
\hline \multicolumn{5}{|l|}{ Experiencing community violence } \\
\hline Positive parenting & -0.030 & $-0.072-0.013$ & 0.022 & 0.172 \\
\hline Food sufficiency & -0.065 & -0.104 to -0.026 & 0.020 & 0.001 \\
\hline AIDS-free caregiver & -0.084 & -0.126 to -0.043 & 0.021 & 0.000 \\
\hline Parental monitoring & -0.046 & -0.087 to -0.005 & 0.021 & 0.029 \\
\hline Teacher support & 0.040 & $-0.001-0.08$ & 0.021 & 0.055 \\
\hline Free schooling & 0.024 & $-0.02-0.068$ & 0.023 & 0.288 \\
\hline Baseline Exp Comm Viol & 0.057 & $0.015-0.1$ & 0.022 & 0.008 \\
\hline
\end{tabular}


Table 2: Path model using multivariate probit regressions with correlated outcomes reporting standardized coefficients using the WLSMV estimator $(n=3396)$ (Continued)

\begin{tabular}{|c|c|c|c|c|}
\hline & Coefficient & $95 \% \mathrm{Cl}$ & S.E. & $p$ value \\
\hline Age & 0.039 & $-0.005-0.083$ & 0.022 & 0.080 \\
\hline Province & -0.414 & -0.467 to -0.362 & 0.027 & 0.000 \\
\hline Urban location & -0.291 & -0.332 to -0.25 & 0.021 & 0.000 \\
\hline Informal housing & -0.063 & -0.111 to -0.016 & 0.024 & 0.008 \\
\hline Sex & -0.022 & $-0.063-0.018$ & 0.021 & 0.282 \\
\hline \multicolumn{5}{|l|}{ School dropout } \\
\hline Positive parenting & -0.046 & $-4.538-4.446$ & 2.292 & 0.984 \\
\hline Food sufficiency & -0.080 & $-7.944-7.784$ & 4.012 & 0.984 \\
\hline AIDS-free caregiver & 0.008 & $-0.827-0.844$ & 0.426 & 0.984 \\
\hline Parental monitoring & -0.020 & $-1.941-1.902$ & 0.980 & 0.984 \\
\hline Teacher support & -0.378 & $-37.417-36.661$ & 18.897 & 0.984 \\
\hline Free schooling & -0.026 & $-2745.612-2745.559$ & 1400.809 & 1.000 \\
\hline Baseline school dropout & 0.146 & $-14.144-14.435$ & 7.291 & 0.984 \\
\hline Age & 0.307 & $-29.8-30.415$ & 15.361 & 0.984 \\
\hline Province & 0.001 & $-0.188-0.191$ & 0.097 & 0.989 \\
\hline Urban location & 0.091 & $-8.844-9.026$ & 4.559 & 0.984 \\
\hline Informal housing & 0.049 & $-4.74-4.838$ & 2.443 & 0.984 \\
\hline Sex & 0.066 & $-6.426-6.559$ & 3.312 & 0.984 \\
\hline \multicolumn{5}{|l|}{ Substance use } \\
\hline Positive parenting & -0.111 & -0.192 to -0.029 & 0.042 & 0.008 \\
\hline Food sufficiency & -0.023 & $-0.084-0.037$ & 0.031 & 0.450 \\
\hline AIDS-free caregiver & -0.031 & $-0.093-0.032$ & 0.032 & 0.339 \\
\hline Parental monitoring & -0.088 & -0.147 to -0.028 & 0.030 & 0.004 \\
\hline Teacher support & -0.003 & $-0.071-0.065$ & 0.035 & 0.930 \\
\hline Free schooling & -0.056 & $-0.127-0.016$ & 0.037 & 0.129 \\
\hline Baseline substance use & 0.044 & $-0.02-0.108$ & 0.033 & 0.180 \\
\hline Age & 0.321 & $0.257-0.384$ & 0.032 & 0.000 \\
\hline Province & -0.258 & -0.353 to -0.164 & 0.048 & 0.000 \\
\hline Urban location & -0.009 & $-0.075-0.057$ & 0.034 & 0.790 \\
\hline Informal housing & -0.080 & -0.147 to -0.012 & 0.034 & 0.020 \\
\hline Sex & -0.135 & -0.201 to -0.069 & 0.034 & 0.000 \\
\hline \multicolumn{5}{|l|}{ Suicidal ideation } \\
\hline Positive parenting & -0.059 & -0.114 to -0.005 & 0.028 & 0.033 \\
\hline Food sufficiency & -0.097 & -0.143 to -0.051 & 0.023 & 0.000 \\
\hline AIDS-free caregiver & -0.104 & -0.148 to -0.061 & 0.022 & 0.000 \\
\hline Parental monitoring & 0.002 & $-0.047-0.052$ & 0.025 & 0.923 \\
\hline Teacher support & -0.048 & $-0.101-0.005$ & 0.027 & 0.075 \\
\hline Free schooling & -0.024 & $-0.078-0.03$ & 0.028 & 0.387 \\
\hline Baseline suicidal ideation & 0.140 & $0.095-0.186$ & 0.023 & 0.000 \\
\hline Age & 0.121 & $0.07-0.173$ & 0.026 & 0.000 \\
\hline Province & -0.102 & -0.175 to -0.029 & 0.037 & 0.006 \\
\hline Urban location & -0.139 & -0.19 to -0.087 & 0.026 & 0.000 \\
\hline Informal housing & -0.032 & $-0.09-0.026$ & 0.030 & 0.283 \\
\hline
\end{tabular}


Table 2: Path model using multivariate probit regressions with correlated outcomes reporting standardized coefficients using the WLSMV estimator $(n=3396)$ (Continued)

\begin{tabular}{|c|c|c|c|c|}
\hline & Coefficient & $95 \% \mathrm{Cl}$ & S.E. & $p$ value \\
\hline Sex & 0.095 & $0.044-0.146$ & 0.026 & 0.000 \\
\hline \multicolumn{5}{|l|}{ HIV risk behaviour } \\
\hline Positive parenting & -0.006 & $-0.065-0.054$ & 0.030 & 0.854 \\
\hline Food sufficiency & -0.060 & -0.11 to -0.011 & 0.025 & 0.017 \\
\hline AIDS-free caregiver & -0.068 & -0.116 to -0.02 & 0.025 & 0.006 \\
\hline Parental monitoring & -0.072 & -0.12 to -0.024 & 0.025 & 0.003 \\
\hline Teacher support & 0.008 & $-0.047-0.063$ & 0.028 & 0.776 \\
\hline Free schooling & -0.087 & -0.144 to -0.03 & 0.029 & 0.003 \\
\hline Baseline HIV risk behaviour & 0.193 & $0.155-0.232$ & 0.020 & 0.000 \\
\hline Age & 0.326 & $0.27-0.383$ & 0.029 & 0.000 \\
\hline Province & -0.162 & -0.235 to -0.088 & 0.038 & 0.000 \\
\hline Urban location & 0.026 & $-0.029-0.081$ & 0.028 & 0.360 \\
\hline Informal housing & 0.004 & $-0.054-0.062$ & 0.029 & 0.891 \\
\hline Sex & -0.166 & -0.219 to -0.114 & 0.027 & 0.000 \\
\hline \multicolumn{5}{|l|}{ TB symptomatic } \\
\hline Positive parenting & -0.029 & $-0.107-0.049$ & 0.040 & 0.465 \\
\hline Food sufficiency & 0.065 & $-0.017-0.148$ & 0.042 & 0.122 \\
\hline AIDS-free caregiver & -0.088 & -0.149 to -0.026 & 0.031 & 0.005 \\
\hline Parental monitoring & -0.013 & $-0.096-0.07$ & 0.042 & 0.763 \\
\hline Teacher support & 0.009 & $-0.066-0.083$ & 0.038 & 0.821 \\
\hline Free schooling & 0.040 & $-0.044-0.123$ & 0.043 & 0.352 \\
\hline Baseline TB symptomology & 0.135 & $0.075-0.196$ & 0.031 & 0.000 \\
\hline Age & -0.012 & $-0.097-0.073$ & 0.043 & 0.780 \\
\hline Province & 0.224 & $0.115-0.333$ & 0.056 & 0.000 \\
\hline Urban location & -0.067 & $-0.154-0.02$ & 0.044 & 0.129 \\
\hline Informal housing & 0.016 & $-0.085-0.116$ & 0.051 & 0.760 \\
\hline Sex & 0.057 & $-0.019-0.132$ & 0.038 & 0.140 \\
\hline
\end{tabular}

Model fit: $X^{2}=258.387, \mathrm{df}=132, p<001, \mathrm{CFI} .967$, TLI .914, RMSEA .017 , WRMR .878

\section{Predicted percentage probabilities of accelerator impacts} on SDG outcomes

The predicted probability of physical abuse in this sample of South African adolescents was 57.2\% (CI 47.2-67.1) with none of the accelerators present (Table 3, Fig. 2). This reduced to 50.9\% (40.2-61.5) when in receipt of positive parenting, 50.9\% (41.660.3) when food secure, 38.4\% (31.3-45.5) when living with an AIDS-free caregiver and 48.7\% (39.4-58.0) when experiencing good parental monitoring. Further reductions were observed for different combinations of two accelerators and greater for different combinations of three accelerators (see Table 3). Where all four accelerators were present, physical abuse exposure reduced to $25.2 \%(19.7-30.7)$. This is a percentage-point reduction of 33.2 (29.0-37.4) from no accelerators present.
The predicted probability of emotional abuse in this sample was 53.0\% (CI 42.8-63.1) with none of the accelerators present (Table 3, Fig. 2). This reduced to $46.1 \%$ (35.4-56.7) when in receipt of positive parenting, $42.6 \%$ (33.2-51.9) when food secure, 31.7\% (25.2-38.2) when living with an AIDS-free caregiver and 44.5\% (35.2-53.7) when experiencing good parental monitoring. Further reductions were observed for different combinations of two accelerators and decreased further for different combinations of three accelerators (see Table 3). Where all four accelerators were present, physical abuse exposure reduced to $13.0 \%(10.0-16.1)$. This is a percentagepoint reduction of $40.0 \%$ (35.9-44.1).

The predicted probability of bullying victimization in this sample was $85.7 \%$ (CI 79.4-91.9) with none of the accelerators present (Additional File 1: Table 3). This reduced to $80.2 \%(72.9-87.5)$ when food secure, $77.4 \%$ 


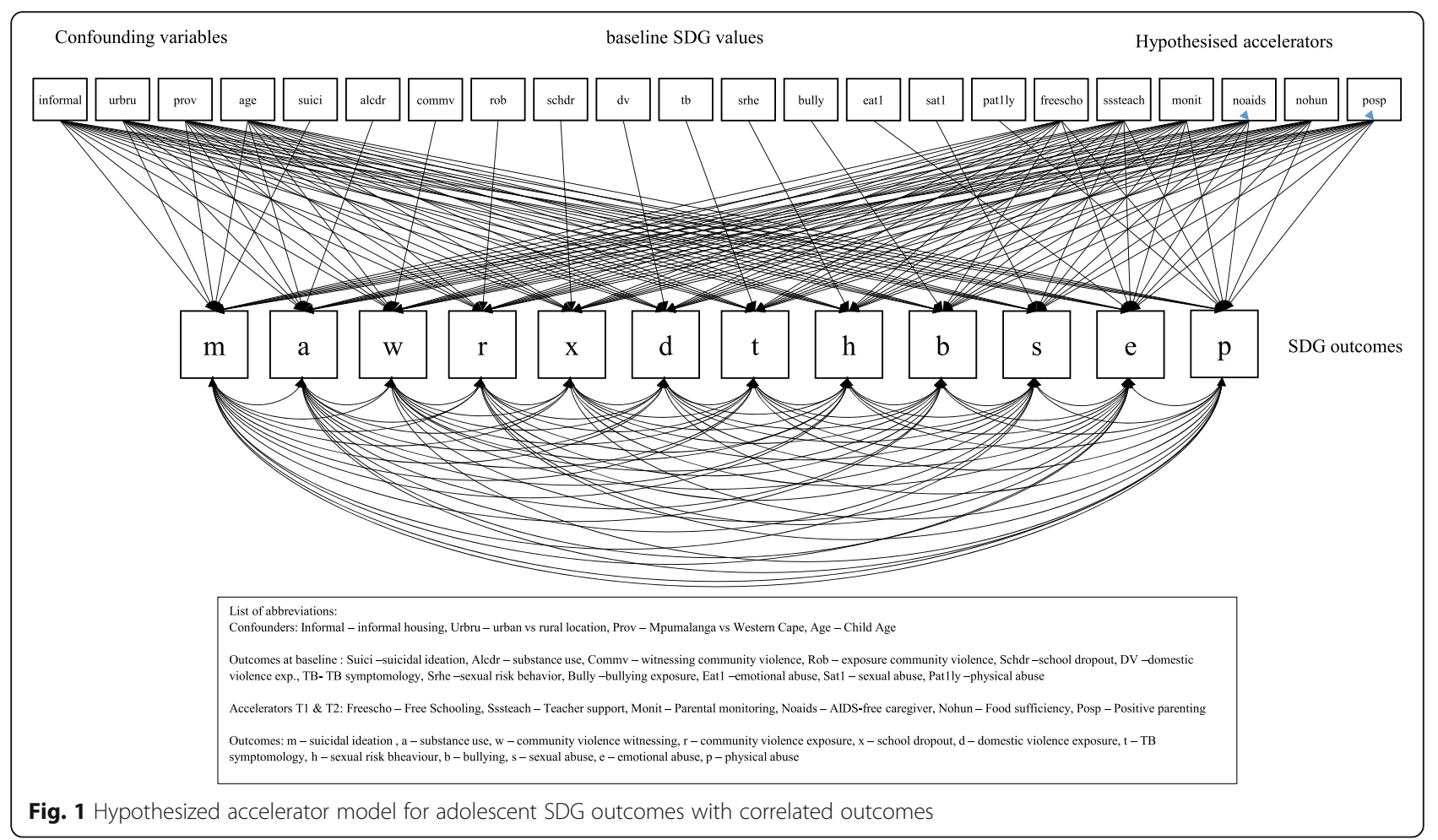

(72.1-82.6) when living with an AIDS-free caregiver and 81.3\% (74.4-88.2) when experiencing good parental monitoring. Further reductions were observed for different combinations of two accelerators (Table 3, Fig. 2). Where all three accelerators were present, bullying victimization reduced to $64.0 \%(59.8-68.3)$. This is a percentage-point reduction of 21.7 (18.7-24.7).

The predicted probability of HIV risk behaviour in this sample was 22.0\% (CI 11.8-32.2) with none of the accelerators present (Table 3). This reduced to $16.7 \%(8.8-$ 24.7) when food secure, $13.3 \%(8.0-18.6)$ when living with an AIDS-free caregiver and 16.3\% (8.2-24.4) when experiencing good parental monitoring. Further reductions were observed for different combinations of two accelerators (Table 3, Fig. 2). Where all three accelerators were present, HIV risk behaviour reduced to $6.5 \%$ (4.1-8.9). This is a percentage-point reduction of 15.5 (13.3-17.7).

The predicted probability of being TB symptomatic in this sample was $5.8 \%$ (CI 1.2-10.4) when no accelerators were present (Table 3). This reduced to $2.5 \%(0.6-4.4)$ when living with an AIDS-free caregiver. This is a percentage-point reduction of $3.3(2.68-3.92)$ in TB symptomatic adolescents.

The predicted probability of witnessing domestic violence was $27.1 \%$ (17.6-36.6) in this sample. Exposure reduced to $17.9 \%(10.7-25.1)$ when food secure and $18.3 \%$ (12.6-24.1) when living with an AIDS-free caregiver. When both accelerators were present, witnessing domestic violence reduced to $11.3 \%(7.5-15.0)$. This is a percentage-point reduction of $15.8(13.0-18.6)$ in domestic violence exposure.

The predicted probability of experiencing community violence was $55.7 \%$ (CI 45.0-66.4) when no accelerators were present (Table 3). This reduced to $47.6 \%$ (37.457.8) when food secure, $39.3 \%$ (32.2-46.4) when living with an AIDS-free caregiver and 50.5\% (40.5-60.5) when experiencing good parental monitoring. This further reduced when combinations of two accelerators occurred (Table 3, Fig. 2). When all three accelerators were present, experience of community violence reduced to $27.2 \%(22.7-31.7)$. This is a percentage-point reduction of 28.5 (25.3-31.7) in community violence experience.

The predicted probability of witnessing community violence was $43.3 \%$ (CI 31.9-54.7) when no accelerators were present. This reduced to $35.3 \%(25.0-45.5)$ when food secure. This is a percentage-point reduction of 8.0 (3.7-12.3) in community violence exposure.

The predicted probability of engaging in substance use was $7.5 \%$ (CI 1.5-13.6) when no accelerators were present. This reduced to $4.2 \%(0.2-8.1)$ when in receipt of positive parenting and $4.6 \%(0.8-8.4)$ when experiencing parental monitoring. When both accelerators were present, substance use reduced to $2.4 \%(0.0-4.7)$. This is a percentage-point reduction of $5.1(3.1-7.1)$ in substance use.

The predicted probability of suffering from suicidal ideation was $32.4 \%$ (CI 22.6-42.3) when no accelerators 
Table 3. Adjusted predicted percentage probabilities for experiencing SDG outcomes and no, one, and all significant accelerators

\begin{tabular}{|c|c|c|c|}
\hline & $\begin{array}{l}\text { Percentage } \\
\text { probability }\end{array}$ & $\begin{array}{l}\text { Confidence } \\
\text { interval }\end{array}$ & $\begin{array}{l}\text { Difference in \% probability compared to } \\
\text { no accelerator }\end{array}$ \\
\hline \multicolumn{4}{|l|}{ Physical abuse } \\
\hline No accelerator & 57.2 & $47.2-67.1$ & \\
\hline Positive parenting & 50.9 & $40.2-61.5$ & $6.1(2.3-9.9)$ \\
\hline Food sufficiency & 50.9 & $41.6-60.3$ & $6.1(1.6-10.6)$ \\
\hline AIDS-free caregiver & 38.4 & $31.3-45.5$ & $18.6(11.6-25.6)$ \\
\hline Parental monitoring & 48.7 & $39.4-58.0$ & $8.3(4.2-12.4)$ \\
\hline Positive parenting \& food sufficiency & 44.6 & $34.8-54.3$ & $12.6(8.6-16.6)$ \\
\hline Positive parenting \& AIDS-free caregiver & 32.5 & $25.2-39.8$ & $24.7(20.9-28.5)$ \\
\hline Positive parenting \& parental monitoring & 42.4 & $32.8-51.9$ & $14.8(10.8-18.8)$ \\
\hline Food sufficiency \& AIDS-free caregiver & 32.6 & $26.8-38.3$ & $24.6(20.7-28.5)$ \\
\hline Food sufficiency \& parental monitoring & 42.4 & $34-50.8$ & $14.8(10.8-18.8)$ \\
\hline AIDS-free caregiver \& parental monitoring & 30.6 & $25.0-36.1$ & $21.2(17.5-24.9)$ \\
\hline Positive parenting, food sufficiency \& AIDS-free caregiver & 27.0 & $21.2-32.8$ & $30.2(26.2-34.2)$ \\
\hline Positive parenting, food sufficiency \& parental monitoring & 36.3 & $27.9-44.7$ & $21.2(17.0-25.4)$ \\
\hline $\begin{array}{l}\text { Positive parenting, AIDS-free caregiver \& parental } \\
\text { monitoring }\end{array}$ & 25.2 & $19.7-30.7$ & $32.0(28.0-36.0)$ \\
\hline Food sufficiency, AIDS-free caregiver \& parental monitoring & 25.3 & $21.1-29.4$ & $31.9(28.7-35.1)$ \\
\hline $\begin{array}{l}\text { Positive parenting, food sufficiency, AIDS-free caregiver \& } \\
\text { parental monitoring }\end{array}$ & 20.4 & $16.4-24.5$ & $32.2(29.0-37.4)$ \\
\hline \multicolumn{4}{|l|}{ Emotional abuse } \\
\hline No accelerator & 53.0 & $42.8-63.1$ & \\
\hline Positive parenting & 46.1 & $35.4-56.7$ & $6.9(3.1-10.7)$ \\
\hline Food sufficiency & 42.6 & $33.2-51.9$ & $10.4(5.9-14.9)$ \\
\hline AIDS-free caregiver & 31.7 & $25.2-38.2$ & $21.3(14.2-28.4)$ \\
\hline Parental monitoring & 44.5 & $35.2-53.7$ & $8.5(4.4-12.6)$ \\
\hline Positive parenting \& food sufficiency & 35.9 & $26.6-45.3$ & $17.1(13.1-21.1)$ \\
\hline Positive parenting \& AIDS-free caregiver & 25.8 & $19.4-32.2$ & $27.2(23.4-31.0)$ \\
\hline Positive parenting \& parental monitoring & 37.7 & $28.4-47.1$ & $15.3(11.3-19.3)$ \\
\hline Food sufficiency \& AIDS-free caregiver & 23.0 & $18.2-27.9$ & $30.0(26.4-33.6)$ \\
\hline Food sufficiency \& parental monitoring & 34.5 & $26.4-42.5$ & $18.5(15.1-21.9)$ \\
\hline AIDS-free caregiver \& parental monitoring & 24.5 & $19.7-29.4$ & $28.5(25.1-31.9)$ \\
\hline Positive parenting, food sufficiency \& AIDS-free caregiver & 18.1 & $13.5-22.7$ & $34.9(31.0-38.9)$ \\
\hline Positive parenting, food sufficiency \&parental monitoring & 28.3 & $20.6-36.1$ & $24.7(20.6-28.8)$ \\
\hline $\begin{array}{l}\text { Positive parenting, AIDS-free caregiver \& parental } \\
\text { monitoring }\end{array}$ & 19.4 & $14.8-24.1$ & $33.6(29.7-37.5)$ \\
\hline Food sufficiency, AIDS-free caregiver \& parental monitoring & 17.1 & 13.8-20.4 & $35.9(32.9-38.9)$ \\
\hline $\begin{array}{l}\text { Positive parenting, food sufficiency, AIDS-free caregiver \& } \\
\text { parental monitoring }\end{array}$ & 13.0 & $10.0-16.1$ & $40.0(35.9-44.1)$ \\
\hline \multicolumn{4}{|l|}{ Bullying } \\
\hline No accelerator & 85.7 & 79.4-91.9 & \\
\hline Food sufficiency & 80.2 & $72.9-87.5$ & $5.5(2.3-8.7)$ \\
\hline AIDS-free caregiver & 77.4 & $72.1-82.6$ & $8.3(3.3-13.3)$ \\
\hline Parental monitoring & 81.3 & $74.4-88.2$ & $4.4(1.3-7.5)$ \\
\hline Food sufficiency \& AIDS-free caregiver & 70.4 & $65.2-75.5$ & $15.3(11.8-18.8)$ \\
\hline Food sufficiency \& parental monitoring & 75.0 & $67.4-82.6$ & $10.7(7.8-13.6)$ \\
\hline
\end{tabular}


Table 3. Adjusted predicted percentage probabilities for experiencing SDG outcomes and no, one, and all significant accelerators (Continued)

\begin{tabular}{llll}
\hline & $\begin{array}{l}\text { Percentage } \\
\text { probability }\end{array}$ & $\begin{array}{l}\text { Confidence } \\
\text { interval }\end{array}$ & $\begin{array}{l}\text { Difference in \% probability compared to } \\
\text { no accelerator }\end{array}$ \\
\hline AIDS-free caregiver \& parental monitoring & 71.7 & $66.8-76.6$ & $14.0(10.7-17.3)$ \\
Food sufficiency, AIDS-free caregiver \& parental monitoring & 64.0 & $59.8-68.3$ & $21.7(18.7-24.7)$
\end{tabular}

\section{HIV risk behaviour}

No accelerator
Food sufficiency
AIDS-free caregiver
Parental monitoring
Food sufficiency \& AIDS-free caregiver
Food sufficiency \& parental monitoring
AIDS-free caregiver \& parental monitoring
Food sufficiency, AIDS-free caregiver \& parental monitoring
B symptomatic

No accelerator

AIDS-free caregiver

Witnessing domestic violence

No accelerators
Food sufficiency
AIDS-free caregiver
Food sufficiency \& AIDS-free caregiver

\section{Experiencing community violence}

No accelerators

Food sufficiency

AIDS-free caregiver

Parental monitoring

Food sufficiency \& AIDS-free caregiver

Food sufficiency \& parental monitoring

AIDS-free caregiver \& parental monitoring

Food sufficiency, AIDS-free caregiver \& parental monitoring

\section{Witnessing community violence}

No accelerators

Food sufficiency

\section{Substance use}

No accelerators

Positive parenting

Parental monitoring

Positive parenting \& parental monitoring

\section{Suicide ideation}

No accelerators

Positive parenting

Food sufficiency

AIDS-free caregiver

Positive parenting \& food sufficiency

Positive parenting \& AIDS-free caregivers

22.0
16.7
13.3
16.3
9.6
12.0
9.3
6.5

$11.8-32.2$

$8.8-24.7$

8.0-18.6

$5.3(1.9-8.7)$

$8.2-24.4$

$8.7(3.8-13.6)$

$5.8-13.3$

$5.7(2.6-8.8)$

$12.4(9.8-15.0)$

$6.1-17.9 \quad 10.0(7.5-12.5)$

$5.6-12.9$

$12.7(10.2-15.2)$

$4.1-8.9$

$15.5(13.3-17.7)$

$1.2-10.4$

$0.6-4.4$

$3.3(2.7-3.9)$

17.6-36.6

10.7-25.1

$9.2(5.7-12.7)$

12.6-24.1

$8.8(3.3-14.3)$

11.3

7.5-15.0

$15.8(13.0-18.6)$
55.7

47.6

39.3

50.5

31.7

42.4

34.4

27.2

\section{3}

45.0-66.4

$37.4-57.8$

$32.2-46.4$

40.5-60.5

25.9-37.5

33.1-51.7

28.5-40.2

22.7-31.7

31.9-54.7

25-45.5

$8.0(3.7-12.3)$

$8.1(3.6-12.6)$

$16.4(9.5-23.3)$

$5.2(1.1-9.3)$

$24.0(20.2-27.8)$

$13.3(9.8-16.8)$

$21.3(17.6-25.0)$

$28.5(25.3-31.7)$

1.5-13.6

$0.2-8.1$

$3.3(1.4-5.2)$

$0.8-8.4$

$2.9(1.1-4.7)$

$0.0-4.7$

$5.1(3.1-7.1)$

$\begin{array}{lll}32.4 & 22.6-42.3 & \\ 27.4 & 17.9-37 & 5.0(1.4-8.6) \\ 23.2 & 15.2-31.3 & 9.2(5.3-13.1) \\ 17.8 & 12.3-23.2 & 14.6(9.1-20.1) \\ 19.1 & 11.6-26.6 & 13.3(9.6-17.0) \\ 14.3 & 9.2-19.4 & 18.1(14.6-21.6)\end{array}$


Table 3. Adjusted predicted percentage probabilities for experiencing SDG outcomes and no, one, and all significant accelerators (Continued)

\begin{tabular}{llll}
\hline & $\begin{array}{l}\text { Percentage } \\
\text { probability }\end{array}$ & $\begin{array}{l}\text { Confidence } \\
\text { interval }\end{array}$ & $\begin{array}{l}\text { Difference in \% probability compared to } \\
\text { no accelerator }\end{array}$ \\
\hline Food sufficiency \& AIDS-free caregivers & 11.5 & $7.8-15.3$ & $20.9(18.0-23.8)$ \\
Positive parenting, food sufficiency \& AIDS-free caregivers & 9.0 & $5.6-12.4$ & $23.4(19.8-27.0)$ \\
\hline
\end{tabular}

were present. This reduced to $27.4 \%(17.9-37.0)$ when receiving positive parenting, $23.2 \%(15.2-31.3)$ when food secure and $17.8 \%$ (12.3-23.2) when living with an AIDS-free caregiver. Further reductions were observed for different combinations of two accelerators (Table 3, Fig. 2). Suicide ideation reduced to 9\% (5.6-12.4) when all three accelerators were present. This is a percentagepoint reduction of 23.4 (19.9-27.0) in suicide ideation.

Across all outcomes where it was a significant accelerator, living with an AIDS-free caregiver was the accelerator contributing to the largest reduction in poor outcomes.

\section{Discussion}

Aiming to achieve even a prioritized subset of the SDGs poses great challenges for lower- and middle-income countries and is even more challenging in countries with the highest HIV prevalence. Compared to upper-income countries, their governments have less tax revenue, and their populations include higher proportions of young people suffering a greater range of deprivations. Accelerators provide an essential opportunity, by identifying how particular interventions that might be undertaken, or particular circumstances that might be improved, can offer significant improvements on three or more SDG targets. Additionally, two or more accelerators may achieve enhanced additive impact on a particular outcome.

This study tested for accelerators among adolescents in especially highly HIV-prevalent and notably deprived communities in South Africa, and identified four accelerators which may aid government in reaching its SDGs in this population: living with an AIDS-free caregiver, food sufficiency, positive parenting, good parental monitoring. Each of these accelerators showed positive associations across at least three out of twelve SDG targets. Firstly, living with a caregiver who was not HIVsymptomatic was the accelerator with the most substantial association across SDG targets. This expands on evidence from South Africa which finds that living with an AIDS-unwell caregiver is associated with a large array of negative outcomes in adolescents [11] and puts children at heightened risk of violence exposure [27, 28]. Conversely, provision of universal access to treatment and testing and early initiation to antiretroviral medication in health systems, such as the 90-90-90 strategy, reduces the number of people with HIV symptomology [29]. It is poignant that the fundamental and essential need of keeping parents alive and healthy appears to be the most impactful accelerator tested in this research.

Secondly, food sufficiency was the accelerator with the next most substantial association across SDG targets. This amplifies a wide array of evidence from subSaharan Africa demonstrating that food sufficiency not only affects nutritional status, growth and weight, but is also strongly correlated with improved educational outcomes [30], improved mental health [31], reduced violence exposure and perpetration [32, 33] and reduced risk behaviours $[33,34]$. Cash transfers and feeding programmes that reduce food insufficiency [35] will likely help governments achieve a number of SDG targets across multiple SDGs, and evidence from randomized trials [36] and other studies investigating accelerators seems to support this [10].

Thirdly, parenting in the form of very positive parenting and very good monitoring showed appreciable associations predominantly across SDG targets related to violence and mental health. This is in line with a growing body of evidence from small-scale evaluations on parenting programmes in sub-Saharan Africa, demonstrating their importance in child and adolescent development. In South Africa, they have been shown to increase positive parenting and parental monitoring which in turn reduce physical and emotional abuse [37], and show reductions in poor mental health expressed through behaviour problems and substance use [38, 39]. Thus far, parenting interventions have shown limited reach and are resource intense which can make their scale-up challenging in places where families experience structural issues. Evidence for the effectiveness of parenting interventions at scale is emerging through the COVID-19 parenting emergency response [40] which has to date reached 193 million people globally and which demonstrates some capacity for scale, with an evaluation in 11 countries showing increased parental engagement and play, more confidence in having positive relationships with their child, less physical abuse and less emotional abuse [41]. In addition, an evaluation of parenting programmes at scale in LMICs is under way [42] as are advances made in a new generation of digital parenting programmes which are yet to be deployed and evaluated but have scope for scale-up through their mechanism of delivery. It is important to note that poor parenting is rarely a choice, but rather an 


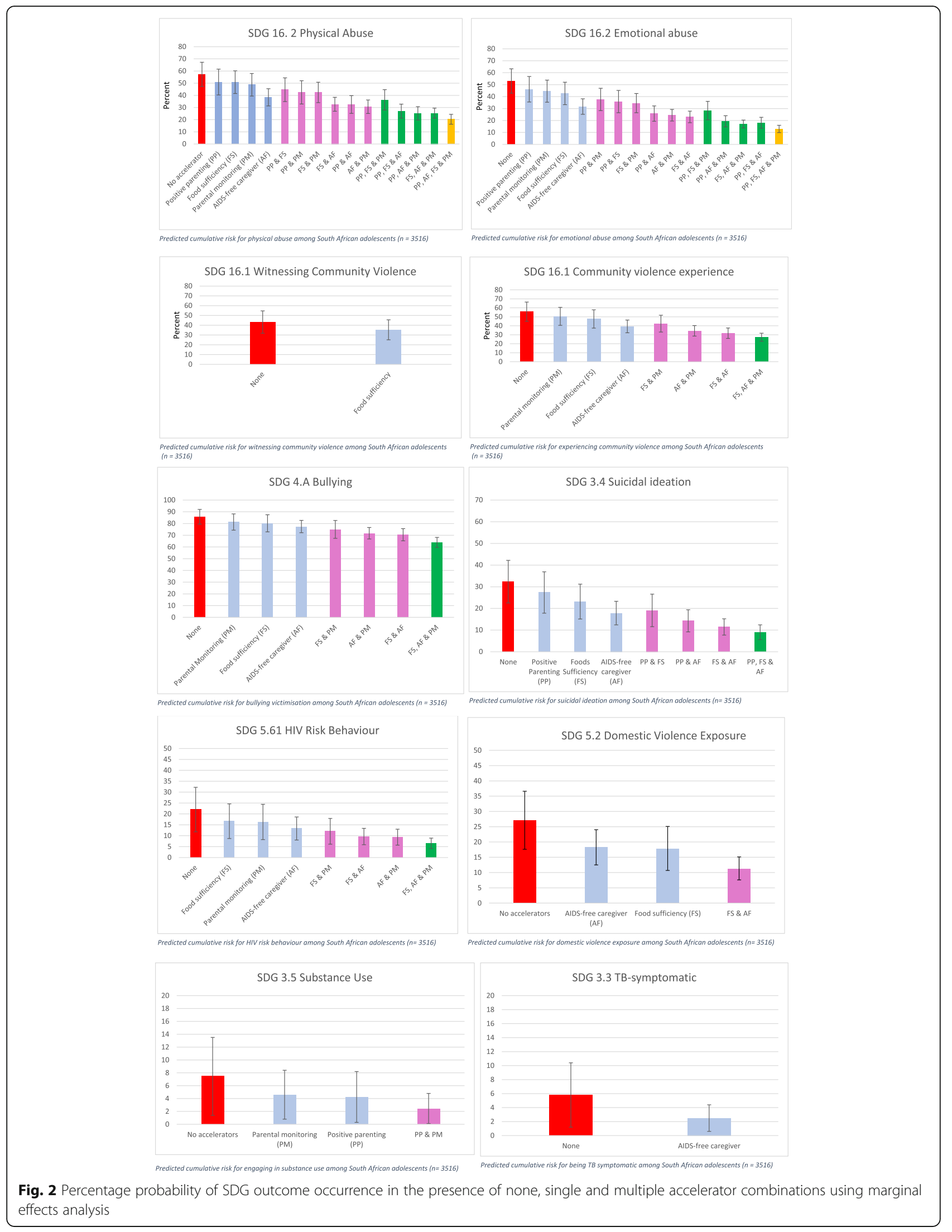


expression of structural issues faced by families such as financial stress, poor health and education systems or unsafe neighbourhoods [43]. Improvements in parenting will likely be seen when these structural issues, over which parents have limited control, are resolved [44].

In addition, this study identified additive effects on SDG targets, of accelerators in combination with each other. For example, food sufficiency was associated with improvements on seven SDG targets, but in combination with one or more of the other three accelerators, improvements on SDG targets were more substantial. This evidence supports that for adolescents to do well, they need to have three fundamental needs met: a parent who is alive and well, enough to eat and receive good parenting. In the context of very high HIV prevalence, none of these can be assumed and as such, these may need to be planned for to be provided together in order to achieve best possible outcomes for adolescents across multiple SDGs and their targets.

Fourthly, free schooling and teacher support were not considered accelerators as they each were not associated with three or more SDG outcomes. Each of these were individually associated with the SDG outcomes but those relationships were not sustained over and above the other pragmatic actions in the full model. These are important interventions in their own right, but in this context, for the purposes of this analysis, good parenting, AIDS-free caregiver and food sufficiency by themselves and in combination were found to be more important and future analyses should investigate this more. A future key area of investigation should focus on determinants of access to each accelerator and combinations of accelerators to allow governments to target populations lacking the presence of these accelerators in order to improve outcomes at the population level.

The path model also tested for moderation effects by sex, using the by-group analysis capability of Mplus. There was no significant difference. This is in contrast to other research from the area, using pooled cohorts, which finds significant differences in accelerators for boys and girls [45].

This study is subject to several limitations. First, the data in this study stem from black African adolescents in deprived settings within two provinces in South Africa. They are therefore not representative of South Africa as a whole. However, the study benefitted from insample variation with regard to location, sociodemographic characteristics, access to accelerators and SDG target outcomes. Second, the data from this study are now 10 years old which may limit the usefulness of the result. While the number of adolescents receiving school meals/free schooling and government cash transfers and access to antiretroviral has significantly increased in the years since the data were collected, the data serve as an important reminder of the importance of universal access to these types of interventions. In addition, there is evidence from recent accelerator studies in South Africa that receipt of cash transfers in areas with 95\% coverage reduces risk for physical and emotional abuse and increases HIV care retention and school progression [10]. Further where state cash transfer coverage is near universal, randomized experiments have shown that impacts of cash transfers increase with the size of the transfer [46] and that additional payments on top of the government grant consistently reduce deprivation among girls in relation to violence, relationships as well as economically [47]. Third, accelerator provision was not based on receipt of interventions except for the free-school provision, but rather on real-world conditions existing in adolescent's lives. Since the provision had to be received across both data collection points, it was not possible to determine whether the positive association of these provisions was due to more sustained or lifelong receipt, and whether provision of specific interventions could achieve the same outcomes. However, hypothesized accelerators were selected on the basis that they address behaviours or shortcomings which could be directly provided through real-world interventions, potentially underpinned by rigorous evidence from randomized experiments. Additionally, the findings do not establish causation. However, they do provide real-world evidence of provisions in which governments can invest, to help them achieve their SDG targets. Fourth, all measures employed in this study use self-report and are as such susceptible to social desirability bias. To mitigate measurement error, the study used validated and piloted measures which had been previously used with adolescents in South Africa and made use of specialist training for interviewers to encourage disclosure and trust in the research project. High retention rates at follow-up speak to the fact that adolescents were comfortable with participation. Fifth, while the study controlled for several potential sociodemographic confounders, the use of adolescent self-report precluded the collection of reliable data on parental income, mental health and educational status and future studies should make use of parent report to address this. Finally, the study conducted multiple-hypothesis testing which can result in erroneous inferences. However, this study corrected for multiple-hypothesis testing and also accounted for correlations among the multiple outcomes reducing the risk of such errors.

\section{Conclusion}

This study demonstrates the potential of four accelerators, positive parenting and parental monitoring, food sufficiency and AIDS-free caregivers. These could translate to three real-world interventions: parenting 
programmes, cash transfers and early HIV treatment initiation and retention. With government commitment, these have shown high acceptability and costeffectiveness. By combining them and expanding reach, governments in sub-Saharan Africa have the potential to assist their rapidly expanding adolescent populations to reach ten targets across four SDGs.

\begin{abstract}
Abbreviations
SDG: Sustainable Development Goals; HIV: Human Immunodeficiency Virus; AIDS : Acquired Immunodeficiency Syndrome; UNDP: United Nations Development Programme; UNICEF: United Nations International Children's Emergency Fund; CECV: Child Exposure to Community Violence Checklist; Mini-Kid: Mini international psychiatric interview for children and adolescents; APQ-SF: Alabama Parenting Questionnaire Short Form; WLSMV: Weighted least squares and variance adjusted; CFI: Comparative model fit; TLI: TuckerLewis index; RMSEA: Root mean square error of approximation; WRMR: Weighted root mean residual
\end{abstract}

\section{Supplementary Information}

The online version contains supplementary material available at https://doi. org/10.1186/s12916-021-02137-8.

Additional File 1: Tables S1-S2: Table S1 - Pairwise correlation matrix. Table S2 - Standardized correlation coefficients between SDG outcomes in the multivariate path model using the WLSMV estimator.

Additional File 2:. Stata and Mplus syntax used for the analysis

\section{Acknowledgements}

We thank all the adolescents who have participated in this research and the local fieldwork teams who collected the data. We also thank Rosie and Gil for writing support and the whole Accelerate Hub Team for furthering the discussion around accelerator analyses.

\section{Authors' contributions}

FM conceptualized the paper and wrote the manuscript. FM, MO, and LC conceptualized the analyses. FM and MO conducted the analyses, and LC provided feedback on the analyses. All authors contributed to the writing of and approved the final manuscript.

\section{Funding}

This study is funded by the European Research Council (ERC) under the European Union's Horizon 2020 research and innovation programme [Grant Agreement Number 852787] and the UK Research and Innovation Global Challenges Research Fund [ES/S008101/1]. Franziska Meinck was also supported by an Economic and Social Research Council (ESRC) Future Research Leader Award [ES/N017447/1]. Lucie Cluver was supported by funding from the European Research Council (ERC) under the European Union's Horizon 2020 research and innovation programme (grant agreement No. 771468 ) and an award jointly funded by the UK Medical Research Council (MRC) and the UK Department for International Development (DFID) under the MRC/DFID Concordat agreement, and by the Department of Health Social Care (DHSC) through its National Institutes of Health Research (NIHR) [MR/R022372/1], UNICEF Eastern and Southern Africa Office (UNICEFESARO) and Oak Foundation GCRF "Accelerating Violence Prevention in Africa" [Grant number: OFIL-20-057]. The Young Carers Study was funded by the Economic and Social Research Council (UK) and the National Research Foundation (RES-062-23-2068), the National Department of Social Development, the Claude Leon Foundation, the Nuffield Foundation (OPD/31598), the Health Economics and HIV/AIDS Research Division at the University of KwaZulu-Natal (R14304/AA002), the John Fell Fund (103/757), the University of Oxford Impact Acceleration Account (1602-KEA-189, 1311-KEA-004 \& 1069GCRF-227) and the Leverhulme Trust (PLP-2014-095). The funding bodies were not involved in the design, data collection, analysis, or interpretation of data, nor involved in writing the manuscript.

\section{Availability of data and materials}

The dataset generated and analysed during the current study are available from the corresponding author on reasonable request. The full dataset for the study is available here:

Cluver, L. (2014). Young carers for AIDS-ill parents: social, health and educational impacts 2010-2013. [data collection]. UK Data Service. SN: 851277, https://doi.org/10.5255/UKDA-SN-851277.

\section{Declarations}

Ethics approval and consent to participate

Ethical clearance was provided by the provincial government departments of Health and Education, the Universities of Oxford (SSD/CUREC2/09-52), Cape Town (389/209) and KwaZulu-Natal (HSS/0254/09). Informed assent was sought from adolescents, and their primary caregiver provided informed consent.

\section{Consent for publication}

Not applicable

\section{Competing interests}

No competing interests to declare.

\section{Author details}

${ }^{1}$ School of Social and Political Sciences, University of Edinburgh, 15a George Square, Edinburgh EH8 9LD, UK. ${ }^{2}$ OPTENTIA, Faculty of Humanities, North-West University, Vanderbijlpark, South Africa. ${ }^{3}$ School of Public Health, University of the Witwatersrand, Johannesburg, South Africa. ${ }^{4}$ MRC-Wits Developmental Pathways for Health Research Unit, School of Clinical Medicine, University of the Witwatersrand, Johannesburg, South Africa. ${ }^{5}$ Centre for Evidence-Based Intervention, Department of Social Policy and Intervention, University of Oxford, Oxford, UK. ${ }^{6}$ Department of Psychiatry and Mental Health, University of Cape Town, Cape Town, South Africa.

Received: 9 May 2021 Accepted: 20 September 2021

Published online: 11 November 2021

\section{References}

1. UNICEF. Adolescent demographics. 2019. https://data.unicef.org/topic/a dolescents/demographics/. Accessed 24 Mar 2021.

2. UNAIDS. Children and HIV fact sheet. 2016.

3. Karim SSA, Baxter C. HIV incidence rates in adolescent girls and young women in sub-Saharan Africa. Lancet Glob Health. 2019;7(11):e1470-1. https://doi.org/10.1016/S2214-109X(19)30404-8.

4. Ministry of Gender, Children, Disability and Social Welfare of the Republic of Malawi, United Nations Children's Fund, The Center for Social Research at the University of Malawi, and the Centers for Disease Control and Prevention. Violence against Children and Young Women in Malawi: Findings from a National Survey, 2013. Lilongwe: Government of Malawi; 2014.

5. Wado YD, Sully EA, Mumah JN. Pregnancy and early motherhood among adolescents in five East African countries: a multi-level analysis of risk and protective factors. BMC Pregnancy Childbirth. 2019;19(1):59. https://doi.org/1 0.1186/s12884-019-2204-z.

6. Owen JP, Baig B, Abbo C, Baheretibeb Y. Child and adolescent mental health in sub-Saharan Africa: a perspective from clinicians and researchers. BJPsych Int. 2016;13(2):45-7. https://doi.org/10.1192/s2056474000001136.

7. UNESCO. New methodology shows that 258 million children, adolescents and youth are out of school. Paris; 2019. http://uis.unesco.org. Accessed 17 Aug 2020

8. Sherr L, Cluver L, Desmond C, Toska E, Aber L, Dhaliwal M, et al. A new vehicle to accelerate the UN Sustainable Development Goals. Lancet Glob Health. 2020;8(5):e637-8. https://doi.org/10.1016/S2214-109X(20)30103-0.

9. UNDP. SDG accelerator and bottleneck assessment. New York; 2017.

10. Cluver LD, Orkin FM, Campeau L, Toska E, Webb D, Carlqvist A, et al. Improving lives by accelerating progress towards the UN Sustainable Development Goals for adolescents living with HIV: a prospective cohort study. Lancet Child Adolesc Heal. 2019;3(4):245-54. https://doi.org/10.1016/ S2352-4642(19)30033-1.

11. Cluver L, Orkin F, Boyes M, Sherr L, Makasi D, Nikelo J. Pathways from parental AIDS to child psychological, educational and sexual risk: 
Developing an empirically-based interactive theoretical model. Soc Sci Med. 2013;87:185-93. https://doi.org/10.1016/j.socscimed.2013.03.028.

12. Cluver L, Doubt J, Wessels I, Asnong C, Malunga S, Mauchline K, et al. Power to participants: methodological and ethical reflections from a decade of adolescent advisory groups in South Africa. AIDS Care. 2020:1-9. https://doi. org/10.1080/09540121.2020.1845289.

13. Snider L, Dawes A. Psychosocial vulnerability and resilience measures for national-level monitoring of orphans and other vulnerable children: recommendations for revision of the UNICEF Psychological Indicator. Cape Town: UNICEF; 2006

14. Finkelhor D, Hamby S, Turner H, Ormrod R. The Juvenile Victimization Questionnaire: 2nd Revision (JVQ-R2). Durham, NH; 2011.

15. Weissberg R, Voyce C, Kasprow W, Arthur M, Shriver T. The Social and Health Assessment (SAHA). Chicago, Illinois; 1991.

16. Richters J, Martinez P. The NIMH community violence project: II. Children's distress symptoms associated with violence exposure. Psychiatry. 1993;56(1): 7-21. https://doi.org/10.1080/00332747.1993.11024617.

17. Sheehan D, Shytle D, Milo K. MINI KID: Mini International Neuropsychiatric Interview for Children and Adolescents. English Version 4.0. University of South Florida, Tampa and Hopital de la Salpetriere, Paris; 2004.

18. Unit RHR. Lovelife. The National Survey of HIV and Sexual Behaviour among Young South Africans. Johannesburg: University of Witwatersrand; 2005.

19. Department of Health Medical Research Council. South Africa Demographic and Health Survey. 2007.

20. Frick PJ. Alabama Parenting Questionnaire. 1991. https://cyfernetsearch.org/ sites/default/files/PsychometricsFiles/Parenting Questionnaire-Alabama (parents of children 6-18)_0.pdf. Accessed 22 Aug 2014.

21. Lopman B, Barnabas R, Boerma T, Chawira J, Gaitskell K, Harrop T, et al. Creating and validating an algorithm to measure AIDS mortality in the adult population using verbal autopsy. Public Libr Sci Med. 2006;3:e312.

22. Seidman E, Allen L, Aber JL, Mitchell C, Feinman J, Yoshikawa H, et al. Development and validation of adolescent-perceived microsystem scales: social support, daily hassles, and involvement. Am J Community Psychol. 1995;23(3):355-88. https://doi.org/10.1007/BF02506949.

23. Statistics South Africa, Statistics South A. Census 2001: Household Questionnaire. Pretoria: Statistics SA; 2001.

24. Teixeira-Pinto A, Normand SLT. Correlated bivariate continuous and binary outcomes: issues and applications. Stat Med. 2009;28(13):1753-73. https:// doi.org/10.1002/sim.3588.

25. Benjamini $Y$, Hochberg $Y$. Controlling the false discovery rate: a practical and powerful approach to multiple testing. J R Stat Soc Ser B. 1995;57(1): 289-300. http://www.jstor.org/stable/2346101. https://doi.org/10.1111/j.251 7-6161.1995.tb02031.x.

26. Brown TA. Confirmatory factor analysis for applied research. New York: Guildford Press; 2015.

27. Meinck F, Cluver L, Boyes M. Household illness, poverty and physical and emotional child abuse victimisation: findings from South Africa's first prospective cohort study. BMC Public Health. 2015;15(1):444. https://doi. org/10.1186/s12889-015-1792-4

28. Skeen S, Macedo A, Tomlinson M, Hensels IS, Sherr L. Exposure to violence and psychological well-being over time in children affected by HIV/AIDS in South Africa and Malawi. AIDS Care. 2016;28(sup 1):16-25. https://doi.org/1 0.1080/09540121.2016.1146219

29. Grinsztejn B, Hosseinipour MC, Ribaudo HJ, Swindells S, Eron J, Chen YQ, et al. Effects of early versus delayed initiation of antiretroviral treatment on clinical outcomes of HIV-1 infection: Results from the phase 3 HPTN 052 randomised controlled trial. Lancet Infect Dis. 2014;14(4):281-90. https://doi. org/10.1016/S1473-3099(13)70692-3.

30. Belachew T, Hadley C, Lindstrom D, Gebremariam A, Lachat C, Kolsteren P. Food insecurity, school absenteeism and educational attainment of adolescents in Jimma Zone Southwest Ethiopia: a longitudinal study. Nutr J. 2011;10(1):1-9. https://doi.org/10.1186/1475-2891-10-29.

31. Weaver $L$, Hadley C. Moving beyond hunger and nutrition: a systematic review of the evidence linking food insecurity and mental health in developing countries. Ecol Food Nutr. 2009;48(4):263-84. https://doi.org/10.1 080/03670240903001167.

32. Hatcher AM, Stöckl H, McBride RS, Khumalo M, Christofides N. Pathways from food insecurity to intimate partner violence perpetration among periurban men in South Africa. Am J Prev Med. 2019;56(5):765-72. https://doi. org/10.1016/j.amepre.2018.12.013.
33. Masa R, Graham L, Khan Z, Chowa G, Patel L. Food insecurity, sexual risk taking, and sexual victimization in Ghanaian adolescents and young South African adults. Int J Public Health. 2019;64(2):153-63. https://doi.org/10.1007/ s00038-018-1155-X.

34. Cluver L, Boyes M, Orkin F, Pantelic M, Molwena T, Sherr L. Child-focused state cash transfers and adolescent risk of HIV infection in South Africa: a propensity-score-matched case-control study. Lancet Glob Heal. 2013;1(6): e362-70. https://doi.org/10.1016/S2214-109X(13)70115-3.

35. Tiwari S, Daidone S, Ruvalcaba MA, Prifti E, Handa S, Davis B, et al. Impact of cash transfer programs on food security and nutrition in sub-Saharan Africa: a cross-country analysis. Global Food Security. 2016;11:72-83. https://doi. org/10.1016/j.gfs.2016.07.009.

36. Peterman A. Neijhoft A (Naomi), Cook S, Palermo TM. Understanding the linkages between social safety nets and childhood violence: a review of the evidence from low- and middle-income countries. Health Policy Plan. 2017; 32(7):1049-71. https://doi.org/10.1093/heapol/czX033.

37. Cluver L, Shenderovich Y, Meinck F, Berezin M, Doubt J, Ward C, et al. Parenting, mental health and economic pathways to prevention of violence against children in South Africa. Soc Sci Med. 2020:113194. https://doi.org/1 0.1016/j.socscimed.2020.113194.

38. Cluver L, Meinck F, Steinert Jl, Shenderovich Y, Doubt J, Herrero Romero R, et al. Parenting for Lifelong Health: a pragmatic cluster randomised controlled trial of a non-commercialised parenting programme for adolescents and their families in South Africa. BMJ Glob Heal. 2018;3(1): e000539. https://doi.org/10.1136/bmjgh-2017-000539.

39. Lachman JM, Wamoyi J, Spreckelsen TF, Wight D, Maganga J, Gardner F. Combining parenting and economic strengthening programmes to reduce violence againstchildren in rural Tanzania: a cluster randomised controlled trial with predominantly malecaregivers. 2020.

40. Cluver L, Lachman JM, Sherr L, Wessels I, Krug E, Rakotomalala S, et al. Parenting in a time of COVID-19. Lancet. 2020;395(10231):e64. https://doi. org/10.1016/50140-6736(20)30736-4.

41. COVID-19 Parenting. COVID-19 Parenting Impact Evaluation. 2021.

42. Shenderovich Y, Ward CL, Lachman JM, Wessels I, Sacolo-Gwebu H, Okop K, et al. Evaluating the dissemination and scale-up of two evidence-based parenting interventions to reduce violence against children: study protocol. Implement Sci Commun. 2020;1 (1):1-11. https://doi.org/10.1186/S43058-02 0-00086-6.

43. Sherr L, Macedo A, Cluver L, Meinck F, Skeen S, Hensels I, et al. Parenting the other oldest profession in the world - a study exploring predictors and ramifications of good parenting on child outcomes. Heal Psychol Behav Med. 2017:5(1):145-65. https://doi.org/10.1080/21642850.2016.1276459.

44. Cucchiara M, Cassar E, Clark M. "'I Just Need a Job!"' Behavioral Solutions, Structural Problems, and the Hidden Curriculum of Parenting Education: https://doi.org/101177/0038040719861363. 2019;92:326-45. doi:https://doi. org/10.1177/0038040719861363.

45. Cluver LD, Rudgard WE, Toska E, Zhou S, Campeau L, Shenderovich Y, et al. Violence prevention accelerators for children and adolescents in South Africa: A path analysis using two pooled cohorts. PLOS Med. 2020;17(11): e1003383. https://doi.org/10.1371/journal.pmed.1003383.

46. UNICEF-ESARO, Transfer Project. Social Cash Transfer and Children's Outcomes: A Review of Evidence from Africa. 2015.

47. Kilburn K, Ferrone L, Pettifor A, Wagner R, Gómez-Olivé FX, Kahn K. The impact of a conditional cash transfer on multidimensional deprivation of young women: evidence from South Africa's HTPN 068. Soc Indic Res. 2020; 151:865-95. https://doi.org/10.1007/S11205-020-02367-Y.

\section{Publisher's Note}

Springer Nature remains neutral with regard to jurisdictional claims in published maps and institutional affiliations. 